portion of sugar, with concomitant indications of favourable progress, are to be deduced from the use of the alkali.

The next case, which was admitted in October of last year, also affords illustration of the advantage to be derived from an alkaline treatment, attention being at the same time paid to diet and regimen; but as these remedies were not administered till after the second class of agents mentioned in the first part of this communication had been tried, it may be more appropriate to present those results first.

Edward $G-$, anged forty-eight, a carpenter, admitted in October, 1552; has been ill and unable to work for three months; complains of great bodily debility and exhaustion, with rapidly-increasing emaciation, inordinate appetite, and most turgent thirst. These are the nsual signs of aggravated diabetes. The skin of the face harsh, dry, and wrinkled, as also in other parts; there is cataract in the left eye; lips cracked and parched; tongue of a bright-red, deficient in moisture, and during sleep becomes adherent to the roof of the mouth; chest narrow, but no signs of lung disease; bowels torpid; dejections dark-coloured; urine clear, faint yellow, specific gravity 1044, contains sugar; the odour of the breath is almost identical with that of chloroform; the urine during the first twenty-four hours measured fifteen quarts. He first took alteratives and salines. He was placed on a double meat diet, and allowed four ounces of bread daily, for which he had a constant craving. He was then ordered twenty drops of glycerine in an ounce of water, to be taken at or immediately after each meal, or whenever he ate anything. The urine had a specific gravity of 1054, and contained twenty-two grains of sugar to the ounce, as estimated by Fehling's process.

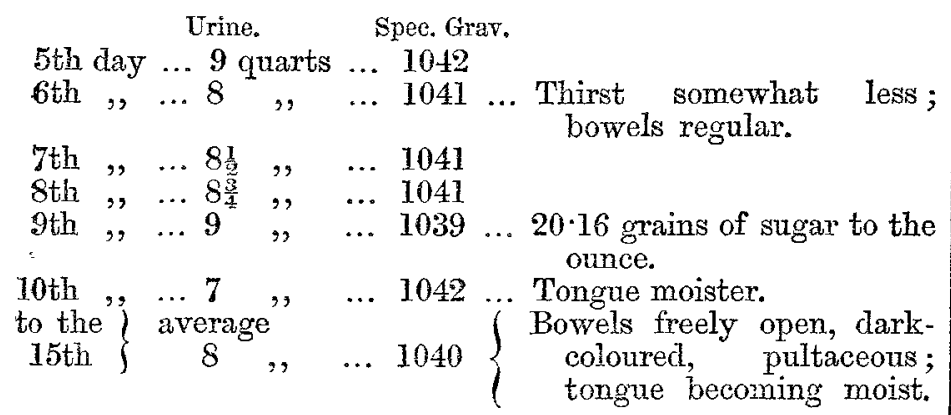

The sulphite of soda, in one-drachm doses, was added to the glycerine, and he took this mixture for seven days; the character of the urine underwent no change; the average daily quantity was eight quarts; one day it rose to twelve quarts and the specific gravity remained as before; and the last sample of urine analyzed gave $19 \cdot 75$ grains of sugar to the ounce. The patient had been three weeks on this treatment without any other than negative results. The remedies were now changed, and opiates were administered. He was ordered a hot bath every evening, and to take a scruple of Dover's powder on getting into bed out of the bath, and fifteen grains in the morning, and again at noon. The bowels were regulated by the compound aloetic draught, with phosphate of soda and aromatic spirit of ammonia.

For the first two days the thirst became more aggravated, but the urine was reduced to seven quarts, and on the third day the skin perspired after the bath, the first damp of moisture, the patient says, that he has felt on his skin since he has been ill. These perspirations continued for six days, occurring in bed an hour after he came out of the bath; the thirst abated; the bowels acted regularly from the medicine. The urine, on an average of eight days, was seven quarts, and specific gravity 1038. The quantity of sugar was estimated at 18.52 grains to the ounce, after he had taken the opium eight days. The bowels became very sluggish, and the patient complained of much exhaustion and debility from the hot baths. These mere discontinued, and as a good deal of headache and irritability of the system became apparent, the opium was discontinued. While taking opiates, the urine diminished in quantity, the specific gravity becoming slightly affected, and the sugar also becoming less, but to a very trifling degree.

In a few days the symptoms of disturbance induced by the opium disappeared, and he took a grain of crude opium three times a day. At first there was some torpor, with contracted pupil, but on the third day the system seemed to tolerate the opium better, and he continued the quantity for ten days. During this period the average daily quantity of urine was seven quarts; and on two occasions, when it was analyzed for sugar, serenteen and fourteen grains to the ounce were calculated. The thirst was much less, and the tongue durisg the day retained a slight moisture; the appetite was more regular, but there was no increase of bodily strength. The head became again affected, and the opium was discontinued. He was now placed on carbonate of ammonia, ten grains; carbonate of potass, ten grains; and carui water, one ounce; to be taken after each meal. He had complained of some gastric uneasiness, while taking the opium, flatulence, and eructations; these symptoms disappeared on taking the alkalies. The urine was at this time of a bright lemon-yellow, and, like the breath, exhaling an odour remarkably like chloroform, but not so powerful as on admission. The average daily quantity was seven and a half to eight quarts; twelve days after taking the alkaline remedies the urine was five quarts, and the specific gravity 1037, and the amount of sugar, 7.53 grains to the ounce; crystals of oxalate of lime were detected by the microscope, and urea was recognised by nitric acid. The bowels were more regular; thirst much diminished, and had become less urgent even at night; the appetite was less craving, but there was no improvement in the physical strength of the patient. He continued the alkalies, with the addition of hard-boiled eggs to his diet, and fish on alternate days, for a further period of nine days, when the specific gravity of the urine was 1038, and the quantity of sugar on two examinations was 6 and 6.5 grains to the ounce. He fancied himself a little better, and as he had been above two months in the hospital, he was desirous of going home, and trying what such a change might do for him. He died three months afterwards, reported from gradual exhaustion.

It would appear from this case that agents which out of the body possess the property of arresting the chemical conversion of sugar, exercise no remedial agency within the organism,at least so far as to diminish the quantity of sugar excreted. It must not be forgotten, however, that observations on a single case are necessarily inconclusive, and particularly as the case just related was one of extreme severity. The action of opiates was at first favourable; the relief to the more distressing symptoms of thirst was evident; the urine became less abundant in consequence, but there was no diminution of the major morbid conditions; emaciation continued, and large quantities, although less than before, of sugar continued to be excreted by the kidneys. The alkaline treatment furnished the most favourable results, - -a gradual diminution in the daily amount of urine and a proportionate decrease in the quantity of sugar present. When he first came under treatment the daily average of sugar passed was 11.25 ounces; after the alkaline treatment it had become reduced to $3 \cdot 66$ ounces in the twentyfour hours. Even this lesser quantity is a large amount of solid sugar to be formed out of the alimentary matters, chiefly animal, taken by the patient. Nevertheless, the great reduction in the amount of fluid excreted, as well as of sugar, formed while under the influence of alkalies, and the larger share of improvement in all respects witnessed as compared with the results observed to follow the use of opium, justify us in placing great reliance on remedies of this class.

(To be continued.)

\section{VALUE OF THE CLTMATE OF EGYPT IN CONSUMPTIVE CASES.}

By WM. E. C. NOURSE, EsQ., M.R.C.S.E.

THE effects of different climates on consumption and other diseases are by no means so perfectly understood as to render further investigation superfluous. On the contrary, they are still so imperfectly known, that every scrap of information has some value. In this belief, I send you a few notes on the climate of Egypt, where I spent the winter of 1851-52. The question of sending a phthisical patient to Egypt not seldom arises in practice.

A visit to Egypt will be of no service unless properly timed and managed, for the climate of that country differs exceedingly in different seasons and latitudes. Supposing the patient to be in a fit state to travel, that he has not gone beyond the preliminary or the first stage of phthisis, can bear a little fatigue, and can disregard a few discomforts and privations, his best time to arrive in Egypt is the month of October. He should leave Cairo for the upper country before December, and go up as high as Thebes, which is the best place for head. quarters in mid-winter, and from whence he may more up the river to the various points of interest. It is hardly advisable to go into Nubia, but if he does so, he should not remain there later than January, as the weather then becomes too lot, and the sand-winds begin to be frequent. For the same reasons he should quit Thebes in February, and drop down the river 
to Cairo. By following precisely this plan, the patient enjoys the advantage of some months of settled weatier and a warm, equable temperature. It is true that the nights are cold, but this evil is easily aroided by not going out after sunset. Cairo and Lower Fgypt are subject to heary rains in winter, with occasionally considerable cold. In spring, when Upper Egypt becomes too hot, they answer very well for the patient to retreat to for six or eight weeks, not longer. Cairo is not advisable after March; the heat becomes very great, and the siroccos (or "khamsin") set in, and the patient should now betake himself to some cooler country.

This, then, is what Egypt is worth for consumptire patients: to arrive in October, go up the country for three months, return leisurely, and leave Egypt by the end of March or beginning of April, but not to be there at any other season. If managed in this way, it secures for the phthisical patient five or six months of a mild, warm, equable climate, with the advantage of an easy mode of travelling amid objects of exceeding interest; but by resorting thither unadvisedly, and being in the different latitudes of that extensive country at a wrong season, mischief is done, or at any rate inconvenience is suffered, and then blame is attributed to the climate, which is rather due either to mismanagement or to the particular case being unsuitable to that country.

At the same time, the value of the climate of Egypt has its limits; it must not be overrated; for to expect of it more than it can do will only cause it to be condemned unjustly. Moreover, there are risks to be guarded against, and precautions to be taken; nor will a residence there do any good to the phthisical patient, unless the diet, clothing, and general management and mode of living are properly regulated accordto the peculiarities of the climate and of the individual case.

Twenty miles south of Cairo, and from thence up the Nile, the climate is rainless. The air is excessively dry, so much so as to render sore and uncomfortable the exposed mucous membranes of the lips and nostrils, and to aggravate the tendency to eruptive disease for which Egypt is noted. These are still the plagues of that country. Even in the cool season, pimples and boils are apt to break out, and accidental sores to be troublesome in healing; and in July, August, and September, whenever the north wind does not blow so steadily as to temper the heat, a painful eruptive complaint, called louton $d u N i l$ prevails. Dust and vermin are both troublesome, and the prevalent ophthalmia is another drawback.

It is much to be wished that means existed of collecting the statistics of the cases of invalids resorting in each season to Egypt, and every other place where patients are sent for the sake of climate. Numerous European invalids were up the Nile the winter I was there, but they had their own medical attendants, and in a few instances only did I come to know anything of them.

One gentleman, extremely emaciated, (apparently a case of extensive tubercular deposits, with great tendency to secondary inflammation, informed me, that the disease appeared to be arrested by his residence in Egypt, that he felt better and stronger, and more capable of exertion, and had gained flesh. I cannot doubt that the fatal termination of his case was considerably retarded by his stay in Egypt. He died in the following November, I believe in Spain.

Another gentleman, of florid complexion, who had been attacked in England with repeated hæmoptysis, became quite free from it in Egypt, and to all appearance perfectly well. He afterwards died of coup-de-soleil, brought on by neglected bowels and over-exertion in the heat of the sun. Both these gentlemen came to Egypt in October, went straight to the upper country, and remained south of Thebes till after Febmary. Then, as the weather got warmer, they descended the Nile and came northwards, intending to quit Egypt for a cooler climate during the summer. They had spent the previous winter in Andalusia, they said with much advantage to their llealth.

Among the native population of Egypt, Mr. Davidson, of Alexandria, says that consumption is only known along the northern sea-board, and is supposed to arise from the extreme humidity of the atmosphere in that region. It does not, however, prevail extensively, and is scarcely met with any other part of Egypt.

Being on the subject of climate, I will add a case showing the eff:cts of the tropical part of the Atlantic. A friend of mine, being threatened with phthisis consequent on pleurisy, took a voyage or two in a vessel sailing between Sierra Leone and the West Indies. He found the most marked benetit from this proceeding, so much so, that $I$ believe if he had remained $n$ that latitude his life might have been spared, for he returned to England comparatively well. His residence in England was in one of the most favourable climatic situations of the south coast; but, notwithstanding inis, his complaints returned under our variable English sky, and at length he died. It may be said that the same result would have occurred had he remained between the tropics; bnt this is matter of opinion, and there are the facts that illness twice came while he lived in the climate of England, whereas a visit to the south was attended with a restoration of health.

Burwood-place, Hyde-park, Dec. 1853.

\section{ANEURISM OF THE AORTA, BURSTING INTO THE PERICARDIUM.}

By WILLIAM HENRY BELLOT, F.R.C.S.E. SURGEON to the 1st. REgr. Cheshire MrLTtra.

ON the morning of September 22,1851 , I was requested to go up to the barracks, to see private $\mathrm{C}-$ - of the 50th (Queen's Own.) I reached there in about a quarter of an hour ; the man had fallen down in his barrack-room, and had just been carried over to the kospital; when I arrived I found him dead.

Before making a post-mortem examination, I was called upon to give my evidence before the coroner; I stated that in my opinion the man had not died from apoplexy, but most probably from some affection of the heart.

On the morning of the man's death he appeared in his usuat excellent health, not having been in the hospital for nearly two years, and then for some totally different and very trifling disease; had never been subject to rheumatism. He was aged twenty-four years; one of the most active men in his company he had brealkfasted as usual at eight A. M.; had been singing, jumping about, and walking upon his hands, \&c.; he then washed, stooped down to brush his shoes, preparing for parade at 10 A.M., fell to the floor, and never spoke again. He was apparently so well, that he had that day requested a pass to visit some friends. Had occasionally complained to his comrades of tightness of the chest, with some little difficulty in breathing when in heavy marching order; sometimes he had slight cough, when he became very red in the face, but never reported himself sick.

Post-mortem examination. The house-surgeon to our infirmary (Mr. Rigby) assisted me in the examination. On opening the chest we found old adbesions of the pleura costalis and pulmonalis, the pericardium strongly adherent, on opening which we found the heart covered and surrounded to the depth of half an inch with coagulated purple blood. There was a true aneurism of the aorta at its commencement of about the size of a small orange, which had burst into the pericardium. The coagulated blood (which was dark-purple) contained in the pericardium, weighed thirteen ounces; the heart itself, and lungs, healthy. On examining the aneurismal sac, we found the internal coats partially destroyed, and the atheromatous matter (described by Mr. Gulliver) was clearly to be seen.

Stockport, Jan. 1854.

\section{POISONING BY TARTAR EMETIC. DEATE; AVTORSY.}

By JOHN S. BEALE, Esq., M.R.C.S.

E. S. S-, aged sixteen years, complained of feeling bilious, and was advised by a nurse to take a dose of tartar emetic; one penny-worth was therefore procured at a chemist's near her residence, on Sunday, Nov. 2lst, and two-thirds taken the same evening at six. Within a quarter of an hour after, yomiting came on, very sharp; and a little while after, smart purging. These symptoms continued for about three hours. The girl also complained of pain down the oesophagus, and described it as "burning her." She then fell asleep. The matter vomited was described as being very dark. On the Monday morning she had some tea, and did not appear to be so ill as to attract attention. Whilst her mother and father were out, on the same afternocn (about four), a neighbour was called in, as she said "she felt as if she was dying." Medical aid was summoned, brandy-and-water ordered, beeftea clysters exhibited, and evarything tried to rally her. Her pulse was thin and cord-like. She kept continually throwing her head back, and screaming. Skin warm and moist; pupils dilated; knees drawn up. Sino lingered till Tuesday morning, 